\title{
On collapse of the inner pipe of a pipe-in-pipe system under external pressure
}

\author{
Mahmoud Alrsai ${ }^{\mathrm{a}}$, Hassan Karampour ${ }^{\mathrm{a}, *}$, Faris Albermani ${ }^{\mathrm{b}}$ \\ ${ }^{a}$ Griffith School of Engineering and Built Environment, Griffith University, Gold Coast Campus, QLD 4222, Australia \\ ${ }^{\mathrm{b}}$ School of Engineering and Technology, Central Queensland University, QLD 4740, Australia
}

Collapse of the inner pipe of a pipe-in-pipe (PIP) system under external pressure is studied experimentally and numerically herein. Hyperbaric chamber test results of three PIP systems with identical inner pipes and different outer pipes are presented. It is observed that the geometric and material properties of the outer pipe affect the collapse pressure of the inner pipe. Using validated finite element analyses (FEA), a parametric study is conducted and collapse mechanisms of PIPs with various combinations of outer and inner pipes with practical range of diameter-to-thickness ratios $(D / t)$ between 15 and 40 are discussed. Empirical expressions are proposed for the collapse pressure of the inner pipe $\left(P_{c i}\right)$, and its upper and lower bounds. The proposed empirical equation for $P_{c i}$, is shown to agree well with the experimental results of the tested PIPs. Moreover, two distinctive modes of collapse in the inner pipe are identified and discussed.

\begin{tabular}{|ll|}
\hline \multicolumn{2}{|l|}{} \\
\multicolumn{2}{|l|}{} \\
$D_{o}$ & outer pipe diameter \\
$D_{i}$ & inner pipe diameter \\
$D$ & nominal outside diameter \\
$t_{o}$ & wall thickness of the outer pipe \\
$t_{i}$ & wall thickness of the inner pipe \\
$E_{o}$ & modulus of elasticity of the outer pipe \\
$E_{i}$ & modulus of elasticity of the inner pipe \\
$E_{o}^{\prime}$ & tangent modulus of the outer pipe \\
$E_{i}^{\prime}$ & tangent modulus of the inner pipe \\
$\sigma_{Y o}$ & yield stress of the outer pipe \\
$\sigma_{Y i}$ & yield stress of the inner pipe \\
$\nu$ & Poisson's ratio \\
$P_{c r}$ & critical collapse pressure of a single pipe \\
$P_{c o}$ & collapse pressure of the outer pipe \\
$P_{c i}$ & collapse pressure of the inner pipe \\
$P_{i n i}$ & initial pressure at the onset of contact between outer \\
$P_{p 2}$ & and inner pipes \\
$V_{o}$ & propagation pressure of the PIP system \\
\hline
\end{tabular}

\footnotetext{
* Corresponding author.

Email address: h.karampour@griffith.edu.au (H. Karampour)
}

\section{$\Delta V \quad$ volume change of the PIP system}

$\Omega_{0} \quad$ ovalization ratio

\section{Introduction}

Subsea pipe-in-pipe systems are preferred to conventional single-walled pipelines due to their superior thermal insulation performance. The PIP system consists of a concentric inner pipe (also known as the product pipe) and the outer pipe (sometimes called the carrier pipe) $[1,2]$. The inner pipe is designed to carry the high temperature and high pressure (HT/HP) of the hydrocarbons inside the pipe. The outer pipe protects the system from external pressure and mechanical damage. The annulus (the space between the tubes) is either empty or filled with non-structural insulation material such as foam or water. Pipe-in-pipe systems are exploited in subsea developments, where the carrier pipe is designed to resist high hydrostatic pressures (water depths up to $3000 \mathrm{~m}$ ) and the inner pipe is designed to transmit hydrocarbons at temperatures as high as $180^{\circ} \mathrm{C}$ and internal pressure up to $10 \mathrm{MPa}$ [3]. The HP/HT flow can cause global upheaval [4,5] or lateral [6-8] buckling of the system.

In a single pipeline under external pressure, a local dent or ovalization in the pipe wall can cause a local collapse. The collapse pressure of a single pipeline $\left(P_{c r}\right)$, with perfectly circular cross-section can be approximated by the classical expression for buckling of elastic tubes under uniform external pres- 
sure [9]:

$$
P_{c r}=\frac{2 E}{1-v^{2}}\left(\frac{t}{D}\right)^{3}
$$

In offshore applications, the pipelines typically have diameter-to-thickness ratios $(D / t)$ ranging from 15 to 40 . It should be noted that, in thick pipes $(15<D / t<20)$, the collapse mechanism is inelastic, and thus Eq. (1) may not yield accurate results [10-13]. In single pipelines, once the buckle is triggered in the pipe, the pipe cross-section is rapidly transformed into a dog-bone shape. The buckle then travels along the pipeline as long as the external pressure is high enough to sustain propagation. The lowest pressure required to perpetuate the buckle is termed propagation pressure, $P_{p}$, which is only a fraction of the collapse pressure. The collapse and propagation of buckling in single pipelines have been extensively investigated using analytical, experimental, and numerical methods. Most notable are the analytical studies by Mesloh et al. [14] and Palmer and Martin [15], the experimental and numerical investigations by Kyriakides and Babcock [16] and Albermani et al. [17], the study of collapse pressure under confined buckling [18], and investigations of interaction between global buckling and propagation buckling of submarine pipelines [19-22].

Unlike single pipelines, collapse mechanisms of PIPs have only been marginally addressed [23-28]. Moreover, these studies have been purely focused on the buckle propagation pressure $\left(P_{p 2}\right)$ of the PIP systems. The existing knowledge on buckling of single-walled pipelines under external pressure can be used to predict the collapse pressure of the outer pipe of a PIP system. However, as will be discussed later in this paper, the buckling mechanisms of the inner pipe and its collapse pressure (referred to as $P_{c i}$ in this paper) are different from those of a single pipeline. To the authors' knowledge there is no existing study on collapse of the inner pipe of a PIP system under external pressure.

The current study aims to provide insight on buckling mechanisms and capacity of a non-pressurised inner pipe within a PIP system, following the collapse of the outer pipe under external pressure. In Section 2 experimental results from hyperbaric chamber tests of three PIPs with different outer pipes and identical inner pipes are presented. In Section 3 , a parametric study on the collapse pressure of the inner pipe $\left(P_{c i}\right)$ is conducted using validated FE analyses, and an empirical expression for $P_{c i}$ is provided. The buckle mechanisms and accuracy of the proposed empirical equation in comparison with the experimental results are discussed in Section 4. The paper is concluded with brief outline of significant outcomes of the study.

\section{Collapse of pipe-in-pipe systems under external pressure: Experimental observations and validation of the finite element analysis}

\subsection{Mechanical properties of the PIPs}

Three sets of concentric aluminium (Al-6060-T5) PIP systems with parameters given in Table 1 were selected for the experimental study. To

compare the collapse pressures of the inner pipes $\left(P_{c i}\right)$ from the three PIPs, identical inner pipes were adopted. The diameter to thickness ratio of outer and inner pipes $\left(D_{o} / t_{o}\right.$ and $\left.D_{i} / t_{i}\right)$, designated by subscript "o" and " $i$ " for outer and inner pipe respectively, are between 25 and 40 which is the practical range in offshore pipeline application. The stress-strain history of the aluminium tubes were obtained from tensile tests conducted on coupon samples (transverse strips), cut from the tubes and having the full thickness of the wall tube according to AS1391-2007 (R2017) [29]. The stress-strain curve of the $80 \times 2 \mathrm{~mm}$ aluminium tube is depicted in Fig. 1a. Since the coupon strips cut from the tube are not flattened, the modulus of elasticity obtained from such tensile test may not always be accurate. Thus, the modulus of elasticity of the samples were obtained from compressive tests of stub columns with length equal to the tube diameter (D), as shown in Fig. 1b. According to AS1391-2007 (R2017)) [29], the length of the stub column should be at least equal to $D / 4$. The modulus of elasticity $(E)$ of the samples listed in Table 1 were obtained from two compressive stub tests (Fig. 1b) conducted for each $D /$ $t$. The material tangent modulus of $E^{\prime}=1 \%$ was adopted for the inner and outer pipes. Previous studies $[17,26,30]$ have shown that the ring squash test is a reliable method to calculate the yield stress in metallic tubes. Therefore, the ring squash test was utilised herein to obtain the yield stress of the samples. The yield stresses were calculated based on results of two ring squash tests (RST) shown in Fig. 2. The ring squash test (RST) $[17,26,30]$ is conducted on a short segment of the pipe specimen compressed between two rigid indenters of the same diameter as the pipe specimen (Fig. 2). The yield stress, $\sigma_{Y}$, is calculated from

$\sigma_{Y}=\frac{F_{0} D}{2 L_{R S T} t^{2}}$

where $F_{0}$ is the RST load shown in Fig. 2 at which the four plastic hinges are developed in the pipe wall. $L_{R S T}$ is the length of the RST sample which is $150 \mathrm{~mm}$ [26]

\subsection{Hyperbaric chamber tests}

The experimental study on collapse of PIPs under external pressure is carried out in a specially designed and fabricated hyperbaric chamber shown in Fig. 3a. The chamber has an inner-diameter of $173 \mathrm{~mm}$ and a length of $4 \mathrm{~m}$ and is rated for working pressure of $20 \mathrm{MPa}(2000 \mathrm{~m}$ water depth). Three sets of concentric aluminium (Al-6060-T5) PIP systems with parameters given in Table 1 and length of $1.6 \mathrm{~m}$ i.e. $L /$ $D_{o}>20$, were end-sealed and pressurized inside the hyperbaric chamber. To end-seal the PIP system, thick aluminium discs were glued to the ends, ensuring that the inner and outer pipes were concentric and that the inner pipe was completely sealed from the outer pipe. To measure the collapse pressures in the outer $\left(P_{c o}\right)$ and inner pipes $\left(P_{c i}\right)$, a set of two valves were connected to the end of each of the outer and inner pipes of the PIP system. For each pipe, one valve was used for bleeding the pipe while filling it with water before the test commence. The second valve was utilized to

Table 1

Geometric and material parameters of PIP systems tested in the hyperbaric chamber.

\begin{tabular}{|c|c|c|c|c|c|c|c|c|c|c|c|c|}
\hline ID & & $\begin{array}{l}D \\
(\mathrm{~mm})\end{array}$ & $\begin{array}{l}t \\
(\mathrm{~mm})\end{array}$ & $D_{o} / t_{o}$ & $D_{i} / t_{i}$ & $\frac{D_{o} / t_{o}}{D_{i} / t_{i}}$ & $D_{i} / D_{o}$ & $t_{i} / t_{o}$ & $\begin{array}{l}E \\
(\mathrm{MPa})\end{array}$ & $\begin{array}{l}E^{\prime} / E \\
(\%)\end{array}$ & $\begin{array}{l}\sigma_{Y o} \\
(\mathrm{MPa})\end{array}$ & $\sigma_{Y i} / \sigma_{Y o}$ \\
\hline \multirow[t]{2}{*}{ PIP-1 } & $\begin{array}{l}\text { Outer } \\
\text { pipe }\end{array}$ & 60 & 2.0 & 30.0 & 25.0 & 1.20 & 0.67 & 0.80 & 66,680 & 1.0 & 139 & 1.12 \\
\hline & $\begin{array}{l}\text { Inner } \\
\text { pipe }\end{array}$ & 40 & 1.6 & & & & & & & & & \\
\hline \multirow[t]{2}{*}{ PIP-2 } & $\begin{array}{l}\text { Outer } \\
\text { pipe }\end{array}$ & 80 & 2.0 & 40.0 & 25.0 & 1.60 & 0.50 & 0.80 & 66,680 & 1.0 & 169 & 0.93 \\
\hline & $\begin{array}{l}\text { Inner } \\
\text { pipe }\end{array}$ & 40 & 1.6 & & & & & & & & & \\
\hline \multirow[t]{2}{*}{ PIP-3 } & $\begin{array}{l}\text { Outer } \\
\text { pipe }\end{array}$ & 80 & 3.0 & 26.7 & 25.0 & 1.07 & 0.50 & 0.53 & 66,680 & 1.0 & 209 & 0.75 \\
\hline & $\begin{array}{l}\text { Inner } \\
\text { pipe }\end{array}$ & 40 & 1.6 & & & & & & & & & \\
\hline
\end{tabular}




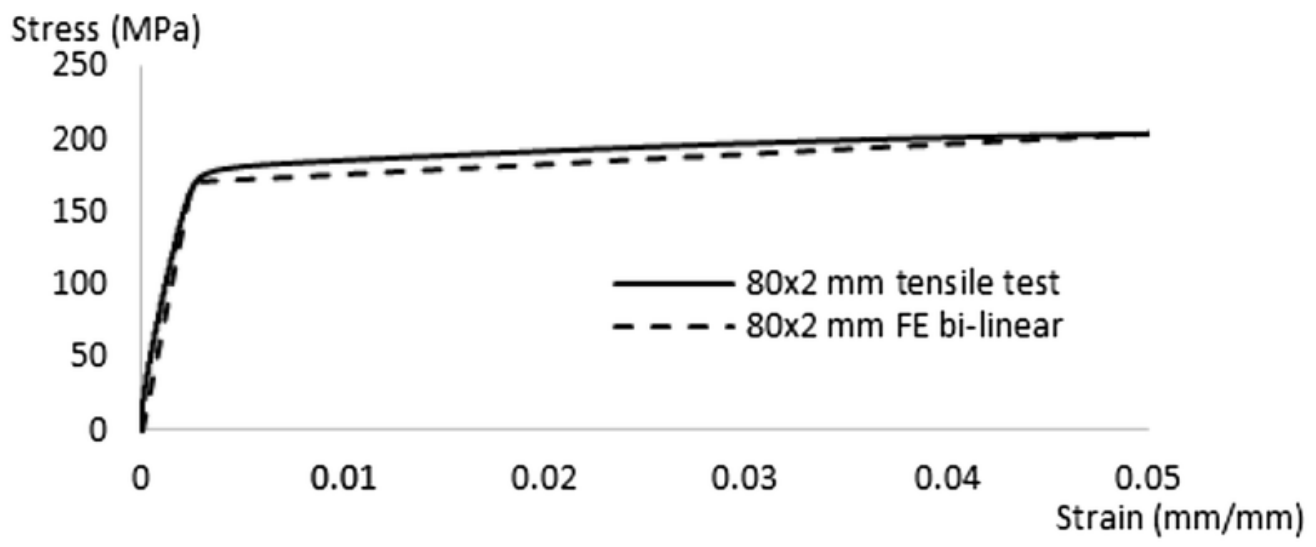

(a)
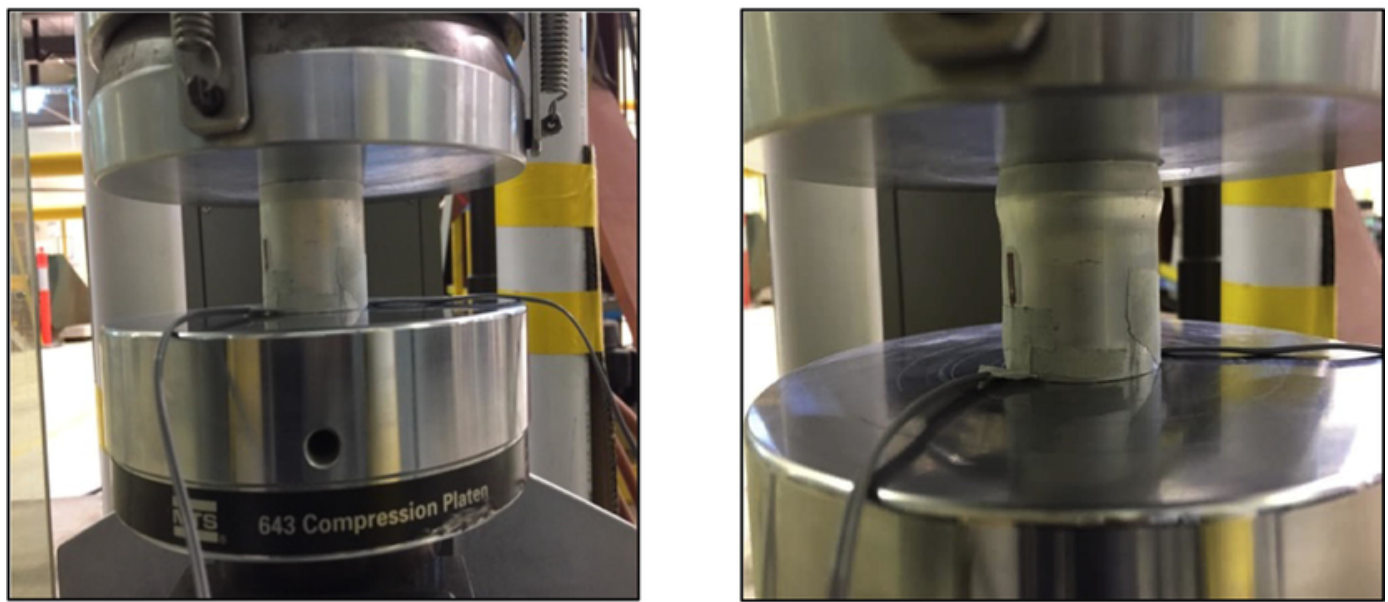

(b)

Fig. 1. (a) Experimental and FE stress-strain curves; (b) Compression stub test, (left) before failure and (right) after failure.

vent each of the carrier and inner pipes, as well as to separately collect water from the inner pipe and the cavity between the inner and outer pipes during the buckle propagation (through the red and black hoses shown in Fig. 3b). A volume-controlled pressurization with a high-pressure pump (shown in Fig. 3a) was used. The change in volume of the system $(\Delta V)$ during the test was calculated by measuring the weight of water being discharged from the inner pipe and the cavity between the pipes separately using digital weighing scales shown in Fig. 3a.

Fig. 4 shows the experimental pressure-volume change response for the outer and inner pipes of PIP-1, 2 and 3, separately. The pressure levels inside the chamber are plotted against the normalized change in volume of the outer pipe, (change in the volume of the annulus and the inner pipe), and that of the inner pipe, separately. Each test was conducted three times and the curves in Fig. 4 show the average values of three tests. As shown in Fig. 4, the pressure initially rises sharply until the collapse pressure $P_{c o}$, is reached at which a section of the outer pipe collapses. Following the collapse of the outer pipe the pressure inside the chamber drops drastically until the outer and the inner pipes come into contact at a pressure level $P_{\text {ini }}$, not shown in the figure. This is followed by the collapse of the inner pipe at collapse pressure $P_{c i}$. The collapse progresses in the outer and inner pipes and quickly spreads throughout the length of the outer and inner pipes at a slightly lower pressure $P_{p 2}$, known as the propagation pressure of the PIP system $[23,25,26,28]$. Longitudinal and cross-sectional views of the deformed shape of PIP-2 are shown in Fig. 4b. Other tested PIPs showed similar deformed patterns.
The collapse pressure in the outer pipe $P_{c o}$, is very sensitive to imperfections in the cross-section of the outer pipe [11-13] which is defined in terms of ovalization ratio $\Omega_{o}$ [31]:

$\Omega_{0}=\frac{D_{\max }-D_{\min }}{D}$

where $D_{\max }$ and $D_{\min }$ are the maximum and minimum diameters of the outer pipe, and $D$ is the nominal outside diameter represented in Table 1. The initial ovality of outer pipes of the tested PIPs were measured as $\Omega_{o}=0.5 \%, 0.2 \%$ and $0.6 \%$ for PIP-1, 2 and 3, respectively. The collapse pressures $\left(P_{c o}\right)$ of PIP-1, 2 and 3 (averages of three tests) are 13\%, 1\% and $16 \%$ lower than the corresponding elastic collapse pressures predicted from Eq. (1) for the outer pipes of each PIP system respectively.

The collapse pressures of the inner pipes $\left(P_{c i}\right)$ measured in the tests are 1645,844 and $2050 \mathrm{kPa}$ for PIP-1, 2 and 3 respectively. These pressures are not the same and are different from the collapse pressure $9578 \mathrm{kPa}$, predicted from Eq. (1). It is observed that although the inner pipes are identical in the three PIP systems used here, their collapse pressures $\left(P_{c i}\right)$ are considerably different. It suggests that the pressure at which the inner pipe collapses is related to the geometric and material properties of the outer pipe of the PIP system. The relation between the collapse pressure of the inner pipe and the parameters of the outer pipe of the PIP system, will be discussed in Sections 3 and 4 of the current study. 


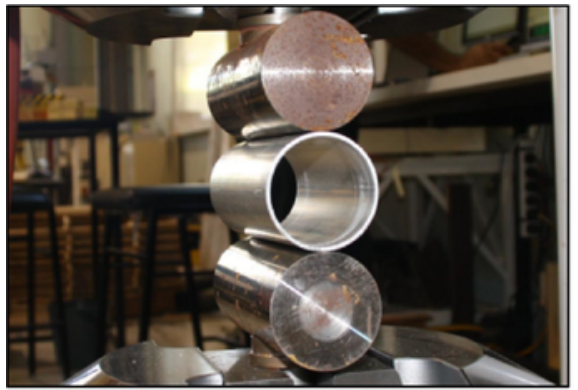

(1)

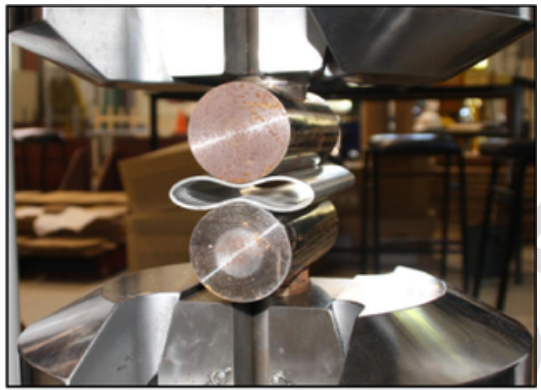

(2)

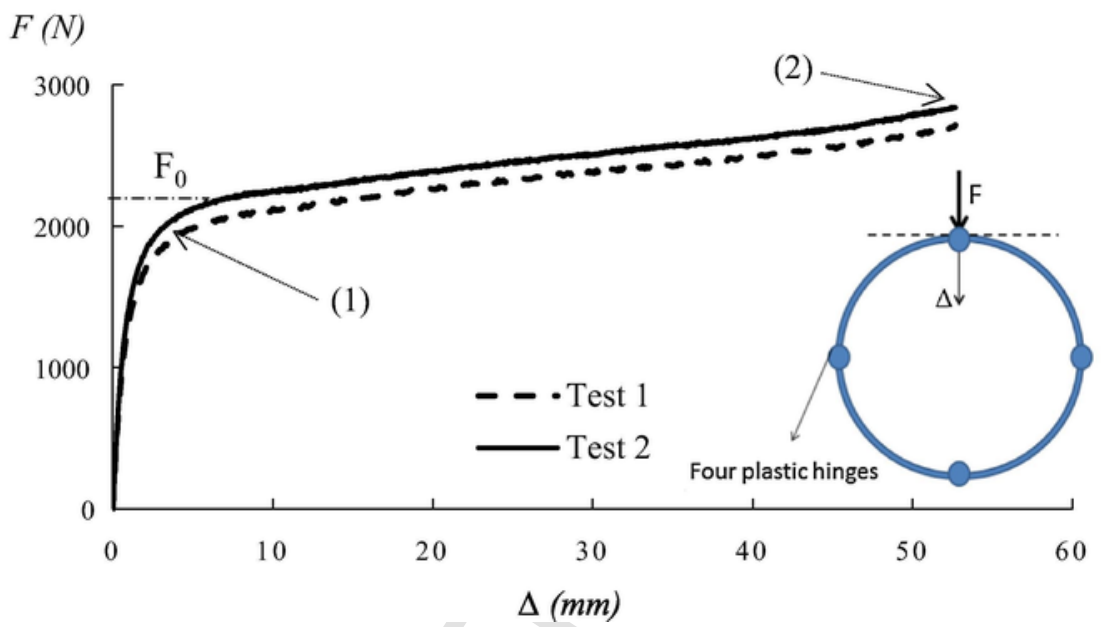

Fig. 2. Ring squash test results, single pipe $(60 \times 2 \mathrm{~mm})$, Initial state 1 (top left), Collapse state 2 (top right) and load deflection response.

\subsection{Finite element model and validation against experimental results of PIP-1}

Numerical simulation of the collapse of PIP-1 tested in the hyperbaric chamber with parameters represented in Table 1 and length of $1.6 \mathrm{~m}$ was conducted in ANSYS [32]. Thin four-node shell elements (181) were used to model the carrier and the inner pipes. Frictionless contact elements (174 and 170) were used in three pairs to define the non-linear contact between the carrier and inner pipes and the inner surfaces of the inner-pipe wall. These contact pairs are shown in Fig. 5b. The first and second pairs are defined between the inner surfaces of the outer pipe and the outer surface of the inner pipe. The third pair considers the contact between the inner top and bottom surfaces of the inner pipe. Because of symmetry, a one-half model of the pipe wall $\left(180^{\circ}\right)$ was discretised using 24 elements in the circumferential direction with seven integration points through the thickness of the carrier and inner pipes. In order to validate the numerical model, the initial ovality of $\Omega_{o}=0.5 \%$ (same as that measured in the test sample and defined in Eq. (3)) was introduced at mid-length on the carrier pipe of PIP-1 in the FE model. The nodes at either end of the PIP system were restrained from translation in all directions. A von-Mises elastoplastic (bilinear) material definition depicted in Fig. 1a and with parameters shown in Table 1 was adopted. To overcome convergence issues, the Arc-Length method [33] which is a strong tool for solving non-linear snap-through buckling problems was used.

The FE response of PIP-1 is plotted in Fig. 5a, corresponding deformed configurations are shown in Fig. 5b, and show good agreement with the experimental results. The collapse pressure of the outer pipe $\left(P_{c o}\right)$, of the inner pipe $\left(P_{c i}\right)$ and the propagation pressure $\left(P_{p 2}\right)$ of PIP-1 from the FE models are presented in Table 2 together with the experimental results. These experimental results are the average of three repeats of hyperbaric chamber tests of PIP-1. Dis- crepancies between the experimental pressures and FE predictions are negligible.

\subsection{Influence of ovality on collapse pressure of the inner pipe}

The dependency of the collapse pressure of the inner pipe $\left(P_{c i}\right)$ to parameters of the outer pipe will be discussed in the next section using a comprehensive parametric study. Prior to the parametric study, the effect of initial imperfection on collapse of a single pipe and that of an inner pipe of a PIP system is investigated using the validated FE analysis. According to recommendations of DNV-OS-F101 [31], ovalities between $0.5 \%$ and $3 \%$ are adopted in the FE models. Collapse pressures of single pipelines with $D / t=15$ and 40 and material properties of Table 1 , are plotted against ovality $\left(\Omega_{0}\right)$, and are shown with dashed lines in Fig. 6 . The collapse pressures are normalised to the elastic critical pressure (Eq. (1)). As expected from previous studies [19,34,35] the collapse pressure of the pipeline decreases with corresponding increase in the cross section ovality. Also, it's worth noting that the expression for elastic buckling pressure (Eq. (1)) does not represent the buckle pressure of the thick single pipe $(D / t=15)$ accurately. Normalised collapse pressures of the inner pipe $\left(P_{c i}\right)$ of PIP systems with the same inner pipe (same as single pipes studied in Fig. 6), and outer pipes with parameters shown, are depicted in Fig. 6 with solid lines. It is evident from Fig. 6 that unlike a single pipeline, the collapse pressure of the inner pipe $\left(P_{c i}\right)$ within the PIP system is not sensitive to imperfections.

3. Parametric study on collapse pressure of the inner pipe $\left(P_{c i}\right)$ of PIPs using finite element analysis

The hyperbaric chamber results disused in the previous section suggest that, the collapse pressure of the inner pipe of the PIP system, $\left(P_{c i}\right)$

is

a

func- 


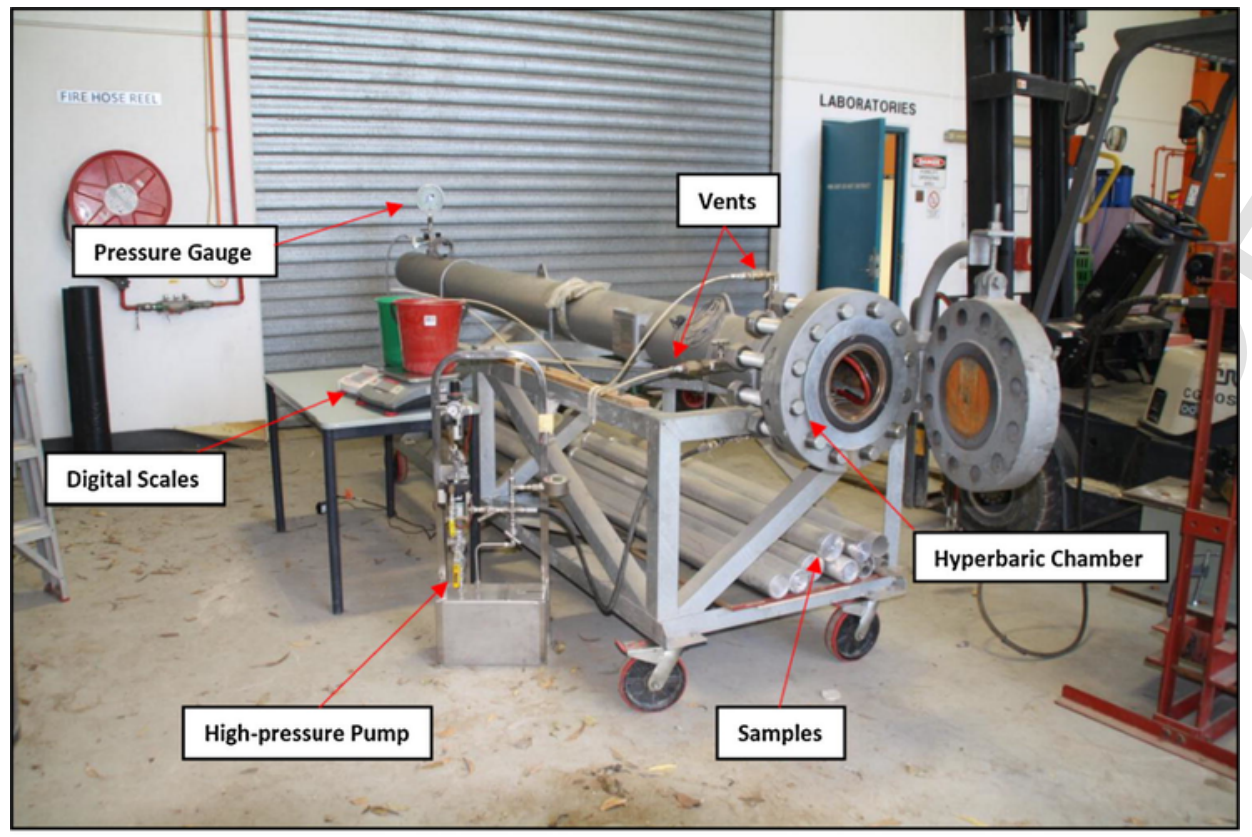

(a)

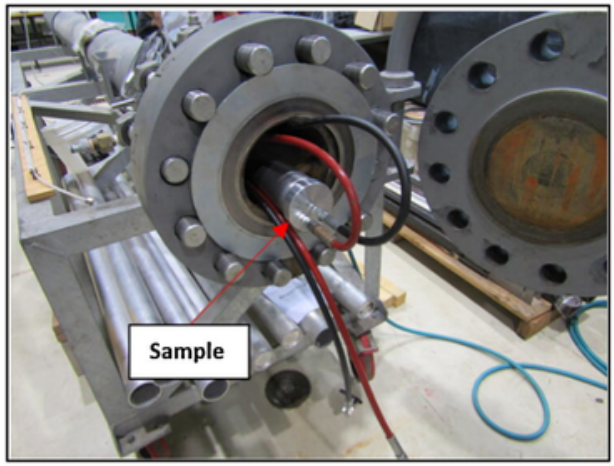

(b)

Fig. 3. Experimental setup (a) hyperbaric chamber, high-pressure pump, scales, pressure gauge, and vents; (b) PIP sample and fittings.

tion of geometric and material parameters of both inner and outer pipes:

$$
P_{c i}=F\left(D_{o}, t_{o}, \sigma_{y o}, E_{o}, E_{o}^{\prime}, D_{i}, t_{i}, \sigma_{y i}, E_{i}, E_{i}^{\prime}\right) .
$$

In the parametric study carried out herein, both outer and inner pipes are assumed to be of the same material i.e. Aluminium (Al-6060-T5). Therefore, the same modulus of elasticity $(E)$ represented in Table 1 and the Poisson's ratio $(\nu=0.33)$ are adopted for all PIPs. Using dimensional analysis, Eq. (4) can be written in terms of three non-dimensional geometric groups and two non-dimensional material groups:

$\frac{P_{c i}}{P c r}=f\left(\frac{D_{i}}{D_{o}}, \frac{t_{i}}{t_{o}}, \frac{D_{i}}{t_{i}}, \frac{\sigma_{y i}}{\sigma_{y o}}, \frac{E_{i}^{\prime}}{E_{o}^{\prime}}\right)$

Obviously, $D_{i} / t_{i}$ can be presented in terms of other two geometric groups in Eq. (5). However, since the collapse pressure of single pipeline is significantly related to the diameter to thickness ratio (Eq. (1)), this term needs to be accounted for in the proposed empirical expression. Knowing that $P_{c i} / P_{c r}<1$, the following constitutional power-law is considered:

$\frac{P_{c i}}{P c r}=A_{1}\left(\frac{D_{i}}{D_{o}}\right)^{a}\left(\frac{t_{i}}{t_{o}}\right)^{b}\left(\frac{D_{i}}{t_{i}}\right)^{c}\left(\frac{\sigma_{y i}}{\sigma_{y o}}\right)^{d}\left(\frac{E_{i}^{\prime}}{E_{o}^{\prime}}\right)^{e}$

Using the validated FE model, a parametric study is conducted herein to establish the best estimates for the unknown power coefficients of Eq. (6).

\subsection{Effect of $D_{i} / D_{o}$}

To explore the influence of the annulus on the collapse pressure of the inner pipe of PIPs, the thickness ratios are varied while the material properties of the two pipes are kept identical. Fig. 7 shows normalised collapse pressures of the inner pipes versus $D_{i} / D_{0}$ for four different $D_{i} / t_{i}$ ratios of $15,25,30$ and 40 and in two sets of $t_{i} / t_{o}$ i.e. 0.8 and 1 . The parametric study covers a practical range of $D_{i} / D_{o}$ between 0.4 and 0.9. A relatively cubic nonlinear relationship is observed between normalised pressure and diameter ratio for both $t_{i} / t_{o}$ values. By decreasing the annulus, the collapse pressure of inner pipe increases considerably, and this is more evident in the PIPs with thin inner pipes (larger $D_{i} / t_{i}$ ). 


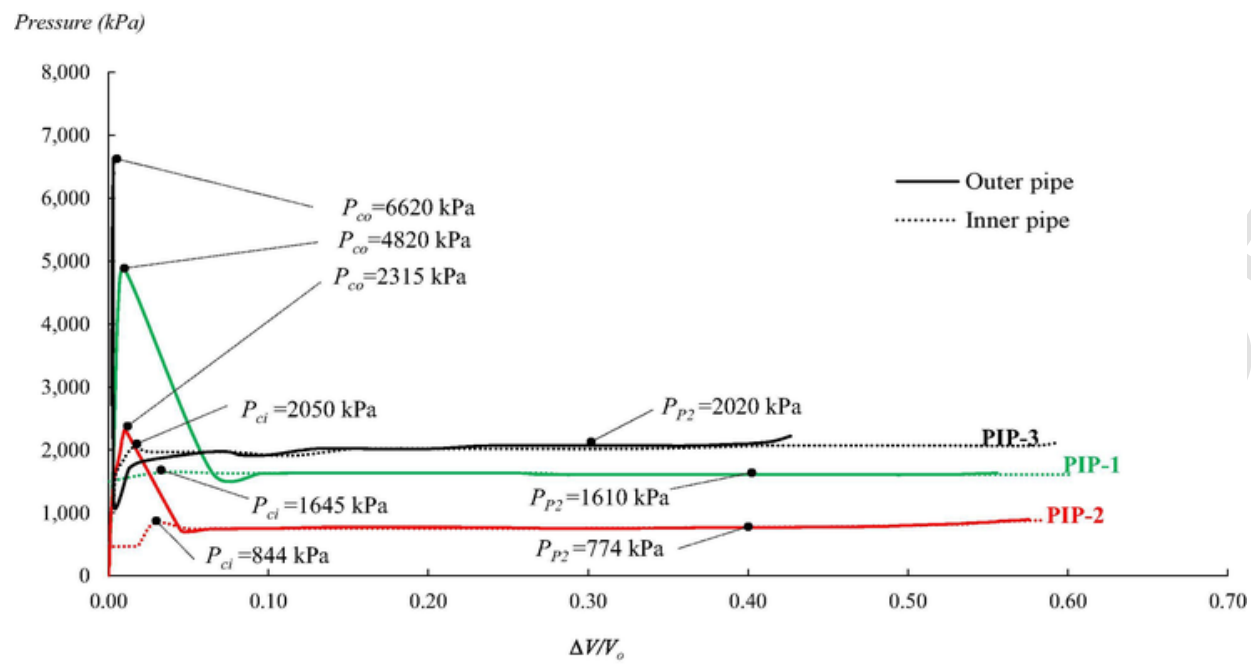

(a)

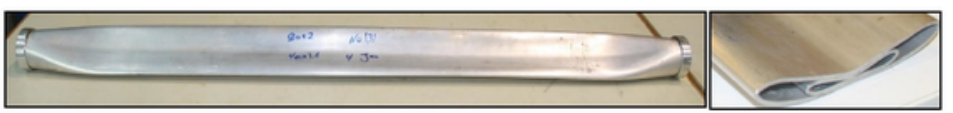

(b)

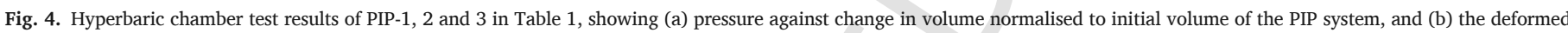
shape of PIP-2.

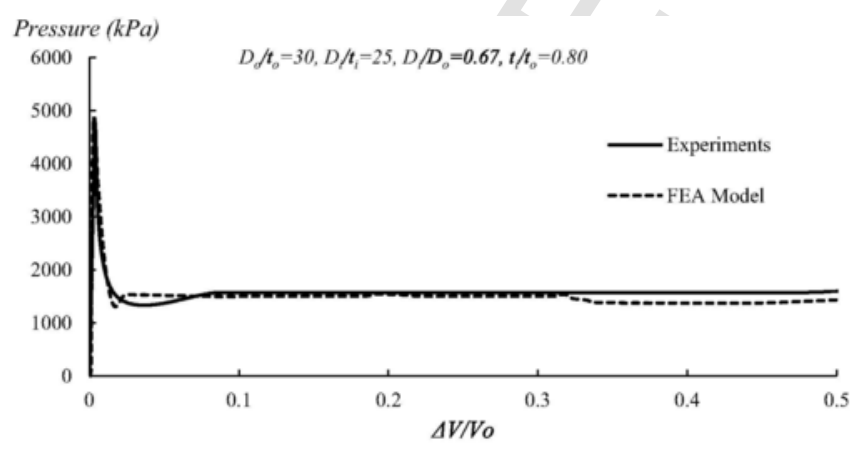

(a)

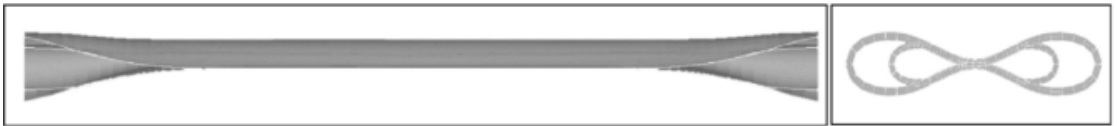

(b)

Fig. 5. (a) Pressure versus normalized change in volume for PIP-1 in Table 1, (b) Deformed shape of the FE model and the frictionless contact pairs.

Table 2

Comparison between experimental and numerical results for PIP-1.

\begin{tabular}{llll}
\hline & Experimental & FEA & FE/Exp \\
\hline$P_{c o}(\mathrm{kPa})$ & 4820 & 4795 & 0.99 \\
$P_{c i}(\mathrm{kPa})$ & 1645 & 1539 & 0.94 \\
$P_{p 2}(\mathrm{kPa})$ & 1610 & 1511 & 0.94 \\
\hline
\end{tabular}

For a fixed value of $t_{i} / t_{o}$ and assuming identical yield stress and tangent modulus in the outer and inner pipes, Eq. (6) is reduced to

$\frac{P_{c i}}{P_{c r}}=A_{2}\left(\frac{D_{i}}{D_{o}}\right)^{a}$
Using non-linear least-squares fitting for eight sets of data in Fig. 7, the coefficients $a=3.2$ and $A_{2}=0.595$ are obtained.

\subsection{Effect of $t_{i} / t_{o}$}

Effect of wall thickness on the collapse pressure of the inner pipe of PIPs is studied for a range of $t_{i} / t_{o}$ between 0.5 and 1.2 and two sets of $D_{i} / D_{0}$. Normalised pressures are plotted against normalised thicknesses in Fig. 8. To generate data-points for each $D_{i} / t_{i}$, diameter of the outer pipe of the PIP system is kept constant (to retain the $D_{i} / D_{o}$ ), and its thickness is changed. In all PIPs, reduction in the thickness of the outer pipe results in a decrease in the collapse pressure of the inner pipe. The decreasing trend in collapse pressure $P_{c i}$, becomes less pronounced as $t_{i} / t_{o}$ approaches 1 . Given the material properties of 


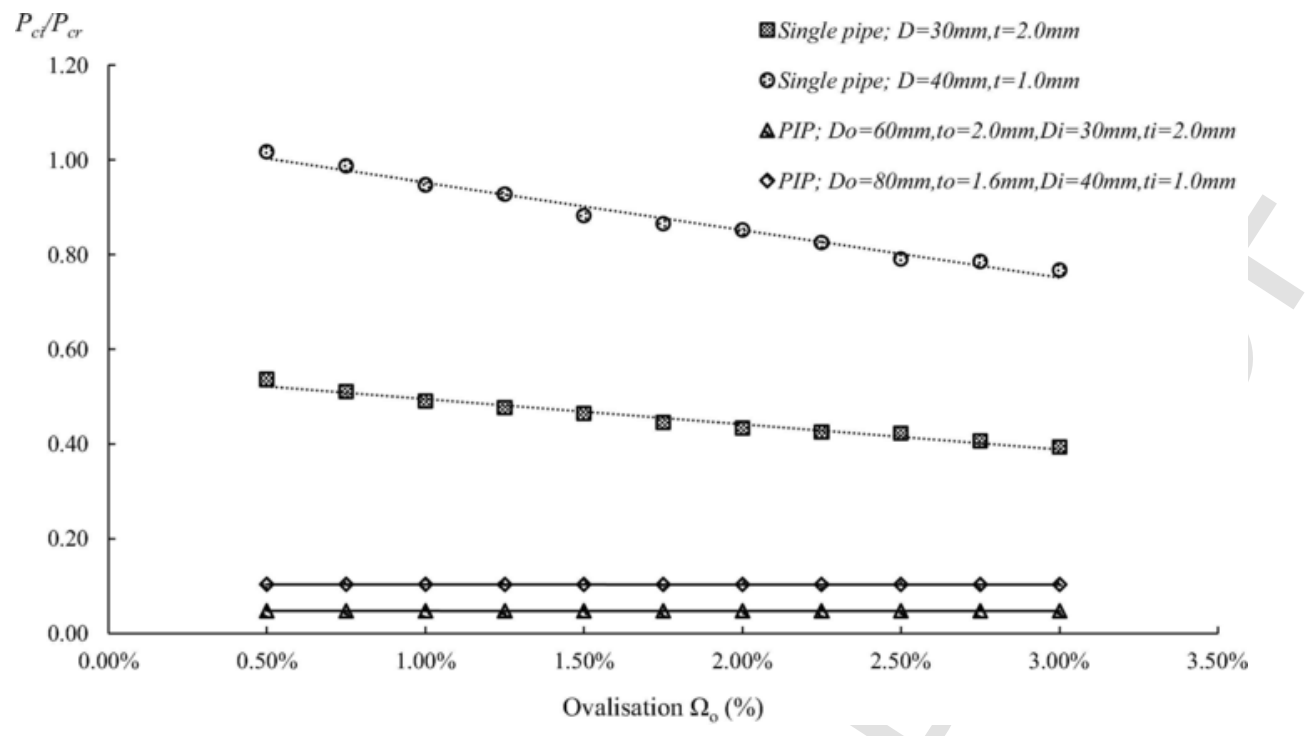

Fig. 6. Normalized collapse pressure vs. ovality curves for single pipe and inner pipe of PIP systems of different $D_{i} / t_{i}$.

the outer and inner pipes are identical, Eq. (6) can be written as

$\frac{P_{c i}}{P_{c r}}=A_{3}\left(\frac{D_{i}}{D_{o}}\right)^{a}\left(\frac{t_{i}}{t_{o}}\right)^{b}$

Using the non-linear least square fitting of the data in Fig. 8, the coefficients $b=-1.88$ and $A_{3}=0.472$ are obtained.

\subsection{Effect of $D_{i} / t_{i}$}

Fig. 9 shows the normalised pressure against $D_{i} / t_{i}$ ratio, for three different $D_{i} / D_{o}$ and in two sets of $t_{i} / t_{o}$. The normalised collapse pressure of the inner pipe increases as the inner pipe gets thinner. This is more pronounced at larger $D_{i} / D_{o}$. Given the material properties of the outer and inner pipes are identical, Eq. (6) can be written as

$\frac{P_{c i}}{P_{c r}}=A_{4}\left(\frac{D_{i}}{D_{o}}\right)^{a}\left(\frac{D_{i}}{t_{i}}\right)^{c}$

Based on the non-linear least squares fitting of the data, the coefficients $c=0.64$ and $A_{4}=0.093$ are obtained.

\subsection{Effect of $\sigma_{y i} / \sigma_{y o}$}

PIPs with $\sigma_{y i} / \sigma_{y o}$ between 0.6 and $1.4, t_{i} / t_{o}$ and $E_{i}^{\prime} / E_{o}^{\prime}$ equal to 1 and in two sets of $D_{i} / D_{o}$ were modelled and the results are shown in Fig. 10. In all PIPs shown in Fig. 10, the collapse pressure of the inner pipe plummets when the yield stress of the outer pipe decreases. To identify the power exponent of $\sigma_{y i} / \sigma_{y o}$, Eq. (6) can be represented as

$\frac{P_{c i}}{P_{c r}}=A_{5}\left(\frac{\sigma_{y i}}{\sigma_{y o}}\right)^{d}$

Based on the total eight sets of data presented in Fig. 10, and using non-linear regression, $d=-0.6$ and $A_{5}=0.474$ are calculated.

\subsection{Effect of $E_{i}^{\prime} / E_{o}^{\prime}$}

Previous studies [11-13] have shown that the pipeline may experience collapse under external pressure, at stress levels beyond the proportional limit. Thus, Eq. (1) is normally modified to account for material corporating the tangent modulus $\left(E^{\prime}\right)[11,12]$. In order to investigate the effect of the tangent modulus on the collapse of the inner pipe, the geometric and yield stress parameters of outer and inner pipes are kept identical and the $E_{i}^{\prime} / E_{o}^{\prime}$ is altered. Results are plotted in Fig. 11 for various $D_{i} / t_{i}$ and with $D_{i} / D_{o}=0.5$. As evident, compared to the thickness, diameter and yield ratios, the tangent modulus has little impact on the collapse pressure $P_{c i}$. Collapse of PIPs with $D_{i} / D_{o}=0.8$ were modelled (not shown here) and no significant changes in results were observed. Knowing that except the tangent modulus, other parameters are unchanged, Eq. (6) can be re-written as

$\frac{P_{c i}}{P_{c r}}=A_{6}\left(\frac{E_{i}^{\prime}}{E_{o}^{\prime}}\right)^{e}$

where $e=-0.3$ and $A_{6}=0.591$ are obtained from least square nonlinear regression.

\subsection{Empirical expression for collapse pressure $P_{c i}$ of PIPs}

The parametric study carried out in previous sections ascertained the dependency of the collapse pressure $P_{c i}$ of the PIP systems on geometric and material parameters of the outer and inner pipes. Based on the results of the parametric study in the previous section and using non-linear square fits of sets of data taken from the FE results, the following normalised expression is derived for the collapse pressure of the inner pipe of PIPs

$\frac{P_{c i}}{P c r}$

$=0.05\left(\frac{D_{i}}{D_{o}}\right)^{3.2}\left(\frac{t_{i}}{t_{o}}\right)^{-1.88}\left(\frac{D_{i}}{t_{i}}\right)^{0.68}\left(\frac{\sigma_{y i}}{\sigma_{y o}}\right)^{-0.6}\left(\frac{E_{i}^{\prime}}{E_{o}^{\prime}}\right)^{-0.3(12)}$

The coefficient (0.05) in Eq. (12) is determined using the Levenberg-Marquardt algorithm with a correlation factor $\left(R^{2}\right)$ of 0.9882 . Comparison between the FE results and the proposed expression (Eq. (12)) is depicted in Fig. 12 for the studied range of $D_{i} / t i$. The maximum difference between FE results and empirical expression (Eq. (12)) is less than $6.0 \%$.The normalised collapse pressures obtained from the proposed empirical expression (Eq. (12)) and those acquired from the hyperbaric chamber for the tested PIPs are represented in Table 3. The differences are less than $5 \%$. As represented in the last column of Table 3 , the empirical expression predicts the experimental results with good accuracy. 


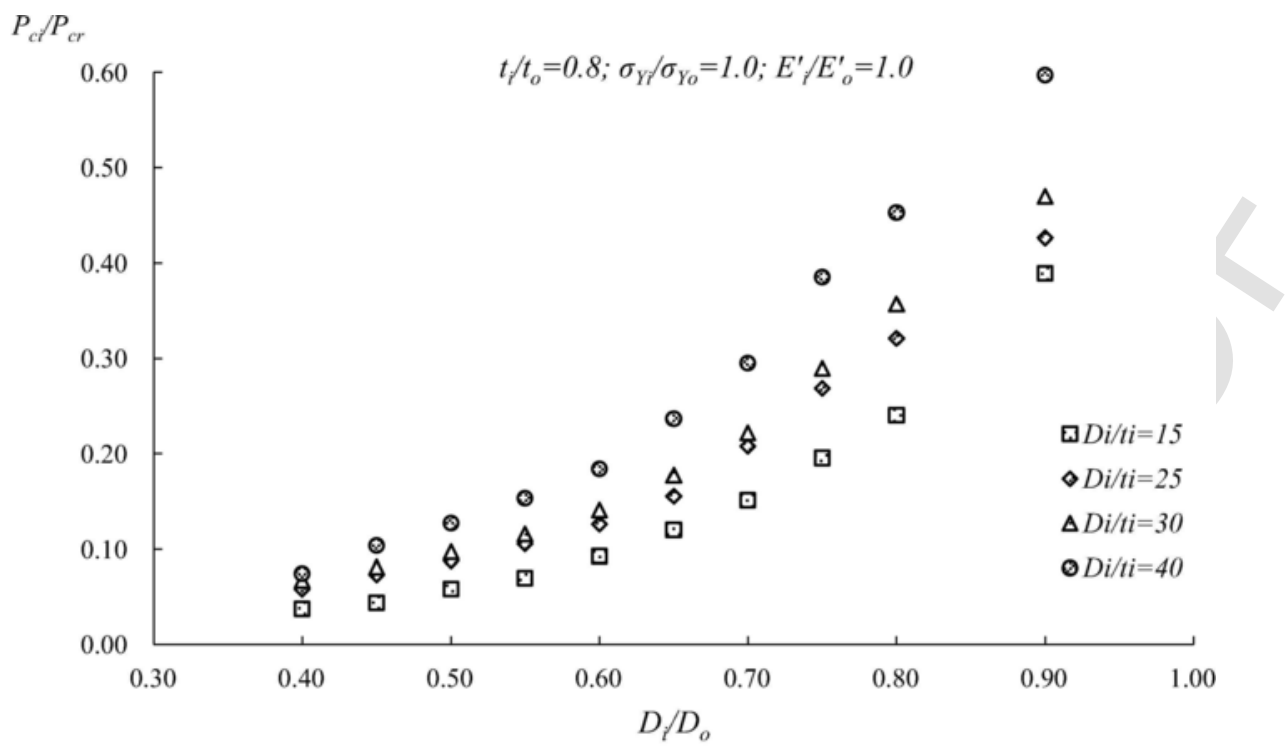

(a)

$P_{c l} / P_{c r}$

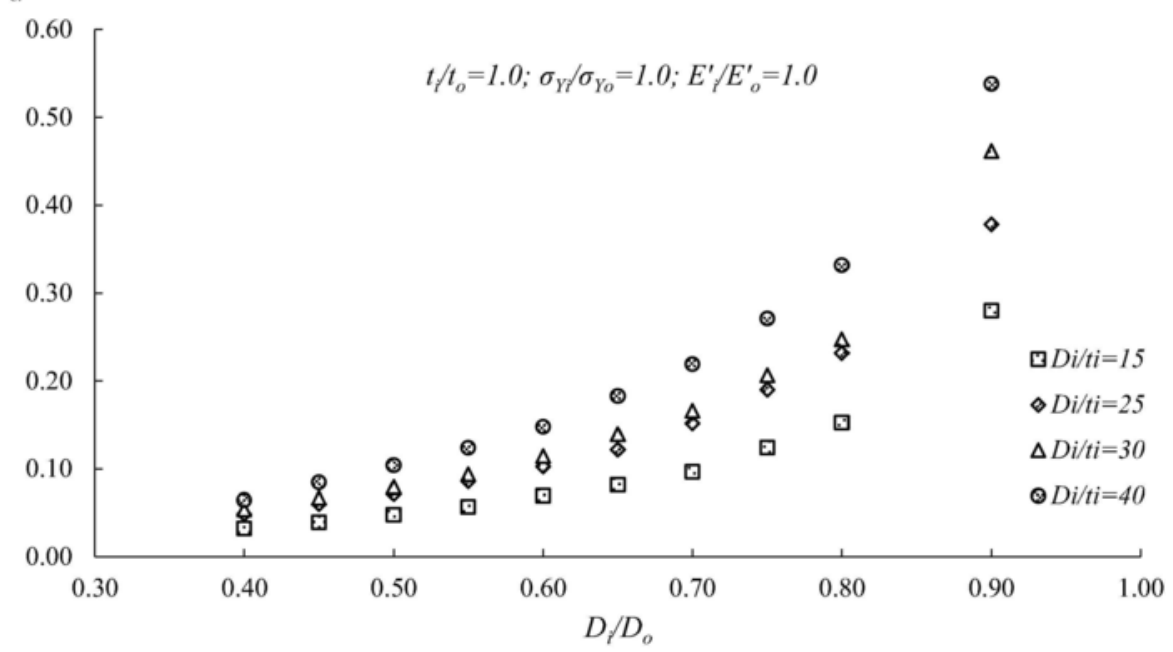

(b)

Fig. 7. Collapse pressure of the inner pipe as a function of $D_{i} / D_{o}$ with (a) $t_{i} / t_{o}=0.8$ and (b) $t_{i} / t_{o}=1.0$.

\section{Discussion of results}

In Section 3, a comprehensive parametric study was conducted using the validated FE model to predict the collapse pressures $\left(P_{c i}\right)$ of PIP systems with various wall thickness $t_{i} / t_{o}$, diameter $D_{i} / D_{o}$, diameter to thickness $D_{i} / t_{i}$, material yield stress $\sigma_{Y i} / \sigma_{Y o}$, and tangent modulus $E_{i}^{\prime} / E^{\prime}{ }_{o}$ ratios. After reviewing results of the parametric dependency of collapse pressures $P_{c i}$ of PIPs, it is worth discussing the collapse modes of the inner pipe observed in the FE simulations. Based on results of FE analyses with various parameters adopted for the outer and inner pipes, two dominant modes of failure under external pressure were observed in the PIPs.

The collapse pressure and deformed shapes of PIPs with $D_{i} / t_{i}$ of 25 and 30 are shown in Fig. 13a and b respectively. In Fig. 13a, the change in the pressure of the system is plotted against the ovality of the inner pipe of the PIP. The collapse mode A is shown for a PIP system with $D_{i} / t_{i}$ of 30 , thickness ratio of $t_{i} / t_{o}=0.8$ and with identical materials properties in outer and inner pipes. In Mode A, by increasing the external pressure, the outer pipe collapses and gradually deforms into the deformed shape (I), at a pressure level called initial pres- sure $P_{\text {ini }}$. At this stage the outer and inner pipes come into contact. Following the touchdown, the pressure stays at the same level (stage II), and the inner pipe collapses at $P_{c i}$ almost equal to $P_{\text {ini }}$. Then, the collapse is propagated along the lengths of the outer and inner pipes simultaneously as shown in stages (III) to (IV) in Fig. 13b for Mode $A$.

Mode B is depicted for the PIP system with $D_{i} / t_{i}$ of 25 and $t_{i} / t_{o}$ of 1.0. The mechanical properties of the inner and outer pipes are alike. In mode B, following the initiation of collapse in the outer pipe, the pressure in the system plunges. Since the corresponding change in ovality of inner pipe only is analysed herein, the associated drop in pressure due to collapse of the outer pipe is not shown in Fig. 13a. At pressure level $P_{\text {ini, }}$ (stages (I) of Fig. 13c) the outer and the inner pipes touch, and the collapse is propagated along the PIP but only in the outer pipe. In the vicinity of the end-caps, a higher pressure is required to perpetuate the collapse in the outer pipe. However, the increase in pressure causes a collapse in the inner pipe as shown in stage (II), at a higher pressure $P_{c i}$ shown in Fig. 13a. The collapse is then propagated through the length of inner pipe (stages (III and IV)). As suggested in Fig. 13a, the collapse pressure $P_{c i}$ is substantially larger than the initial pressure $P_{i n i}$ in failure mode $\mathrm{B}$, compared to mode $\mathrm{A}$. 


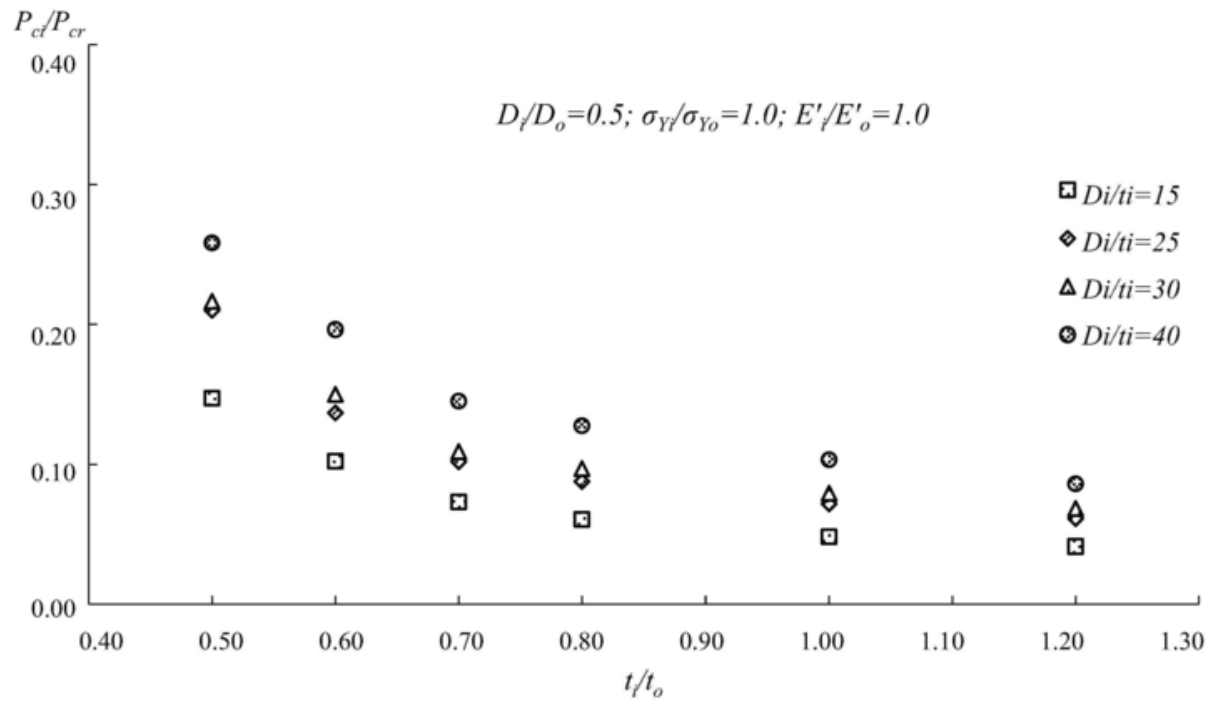

(a)

$P_{c l} / P_{c r}$

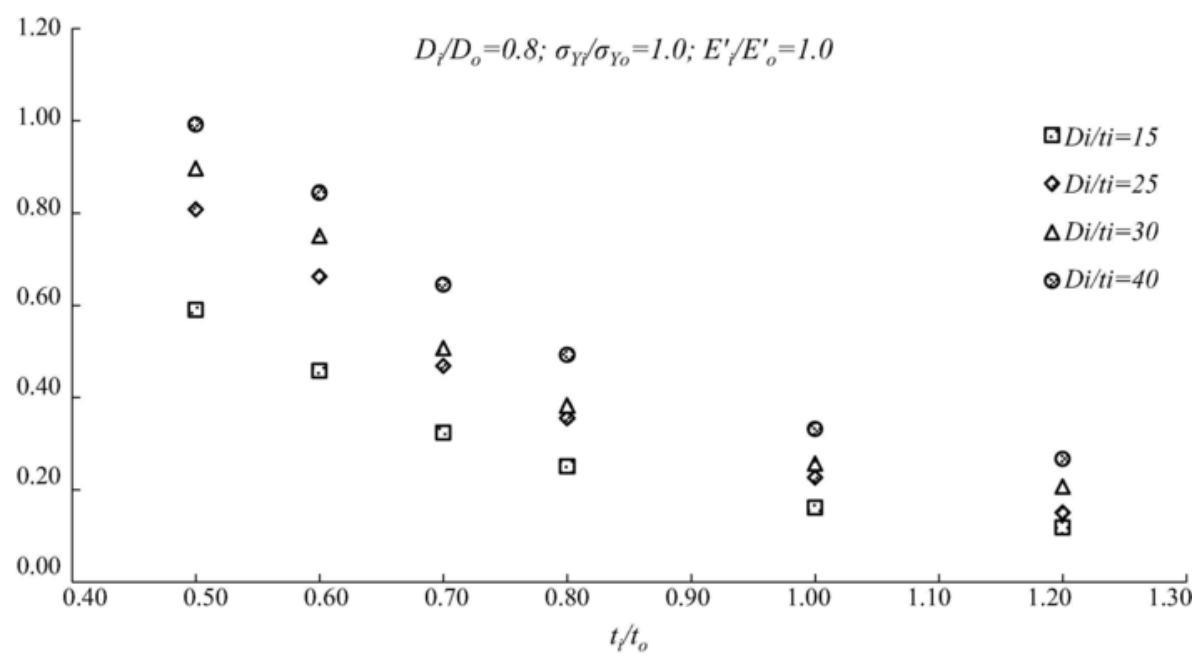

(b)

Fig. 8. Collapse pressure of the inner pipe as a function of $t_{i} / t_{o}$ with (a) $D_{i} / D_{o}=0.5$ and (b) $D_{i} / D_{o}=0.8$.

To understand the distinction between modes A and B, collapse mechanisms of PIPs with outer and inner pipes of similar mechanical properties are investigated. Collapse pressures normalized by the initial pressures of the inner pipe of PIP systems with $\sigma_{y i} / \sigma_{y o}=1.0, E_{i}^{\prime} / E_{o}^{\prime}=1.0$ and thickness ratios between 0.3 and 1.2 are presented in Fig. 14. The results correspond to four sets of $D_{i} / t_{i}$ and two sets of $D_{i} / D_{o}$. With respect to Fig. 13, the collapse modes $A$ and $B$ are associated with $P_{c i} / P_{i n i} \approx 1$ and $P_{c i} / P_{i n i}>1$, and correspond to $t_{i} / t_{o} \leq 0.7$ and $t_{i} / t_{o}>0.7$ respectively as shown in Fig. 14. It can be inferred from Fig. 14, that in PIPs with outer and inner pipes of similar material properties, the separation between collapse modes $A$ and $B$ occurs at thickness ratio $t_{i} / t_{o}=0.7$. Regardless of $D_{i} / t_{i}$ ratio, the upsurge in $P_{c i} / P_{i n i}$ at $t_{i} / t_{o}>0.7$, is more pronounced in PIPs with smaller $D_{i} / D_{o}$ (i.e. larger annulus).

Fig. 15 shows the normalized collapse pressures of the inner pipe against the normalized diameter-to-thickness ratios of outer and inner pipes, for 150 PIPs with $0.3 \leq t_{i} / t_{o} \leq 1.2$ and $0.4 \leq D_{i} / D_{o} \leq 0.9$. As suggested by the trend in Fig. 15, when the outer pipe of the PIP is thinner than the inner pipe, $\left(D_{o} / t_{o}>D_{i} / t_{i}\right)$, failure mode B occurs in the PIP. The distinction between failure modes A and B corresponds to $D_{0} / t_{o}=1.25$ $D_{i} / t_{i}$ in Fig. 15.

The upper and lower bounds of data points in Fig. 15 can be estimated, assuming the material properties of the outer and inner pipe identical.
Eq. (12) can be written as

$\frac{P_{c i}}{P c r}=0.05\left(\frac{D_{i}}{D_{o}}\right)^{1.32}\left(\frac{D_{i}}{t_{i}}\right)^{0.68}\left(\frac{D_{o} / t_{o}}{D_{i} / t_{i}}\right)^{-1.88}$

In the current study and in practical PIPs, $D_{i} / D_{o}$ and $D_{i} / t_{i}$ range between $0.4-0.9$ and 15-40, respectively. Inserting $D_{i} / D_{o}=0.9$ and $D_{i} / t_{i}=40$ in Eq. (13), the upper bound can be predicted by Eq. (14):

$\frac{P_{c i}}{P c r}=0.534\left(\frac{D_{o} / t_{o}}{D_{i} / t_{i}}\right)^{-1.88}, \quad 0.5<\frac{\left(D_{o} / t_{o}\right)}{\left(D_{i} / t_{i}\right)}<2.0$

The lower bound is obtained by adopting $D_{i} / D_{o}=0.4$ and $D_{i} / t_{i}=15$ in Eq. (13), and can be shown with the following expression:

$\frac{P_{c i}}{P c r}=0.095\left(\frac{D_{o} / t_{o}}{D_{i} / t_{i}}\right)^{-1.88}, \quad 0.5<\frac{\left(D_{o} / t_{o}\right)}{\left(D_{i} / t_{i}\right)}<2.0$

Eqs. (14) and (15) are shown with solid lines in Fig. 15 and provide upper and lower bounds of the FE results. 


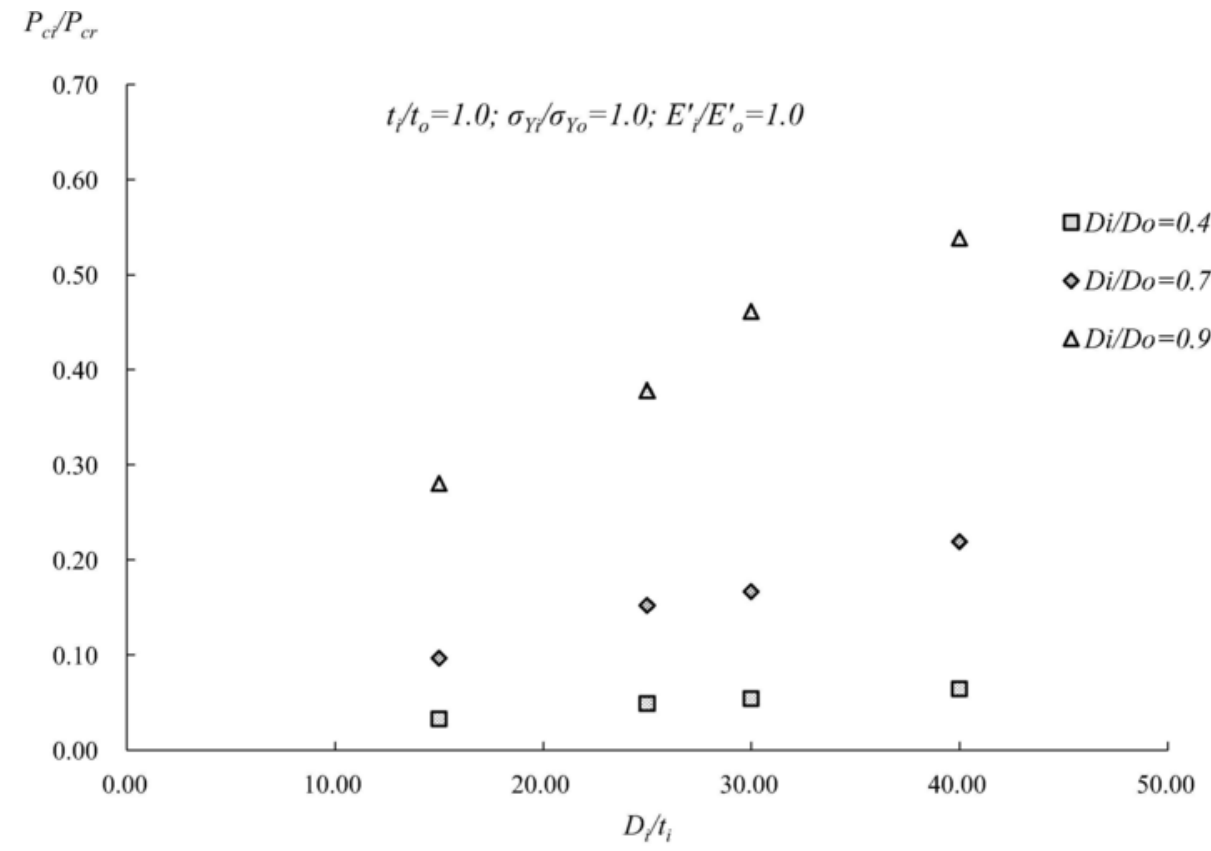

$P_{c} / P_{c r}$

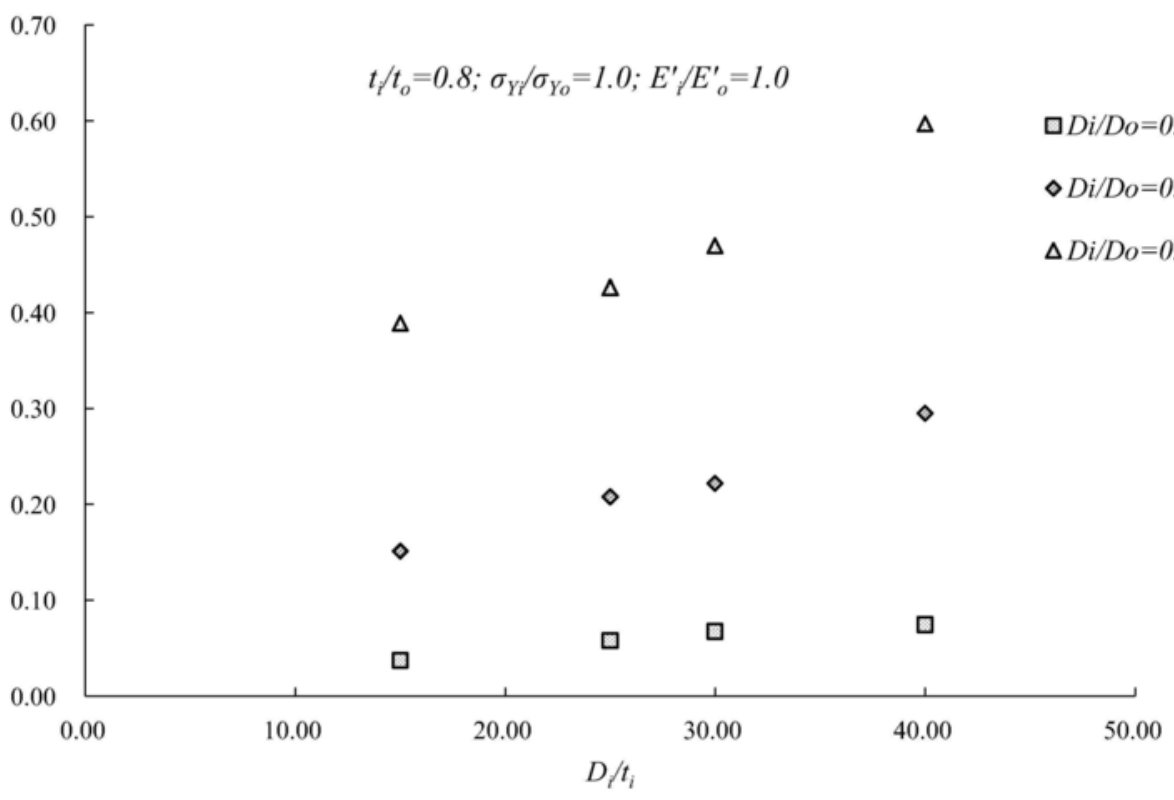

(b)

(a)

\section{Conclusions}

The buckling mechanisms and capacity of the inner pipe of the PIP system, under external pressure were investigated experimentally and numerically herein. The hyperbaric chamber test results showed that in PIPs with identical inner pipes and different outer pipes, the inner pipe may collapse at different pressures $\left(P_{c i}\right)$. To find an expression for $P_{c i}$ a comprehensive parametric study was conducted using validated nonlinear geometric and material FE analyses. In the parametric study, effect of the wall thickness $t_{i} / t_{o}$, diameter $D_{i} / D_{o}$, diameter to thickness $D_{i} / t_{i}$, material yield stress $\sigma_{Y i} / \sigma_{Y o}$, and tangent modulus $E_{i}^{\prime} / E_{o}^{\prime}$ ratios, on collapse pressure of the inner pipes were investigated. It was understood that unlike single pipelines, the collapse pressure of the inner pipe 


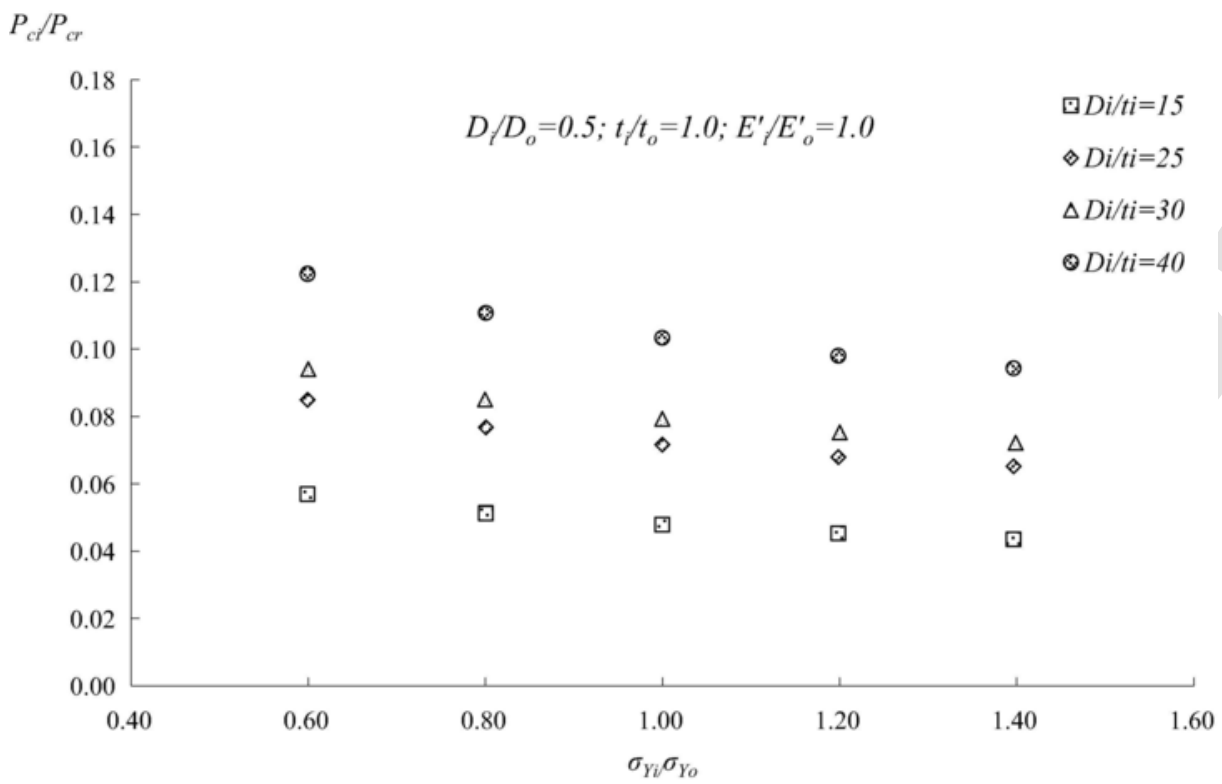

$P_{c i} / P_{c r}$

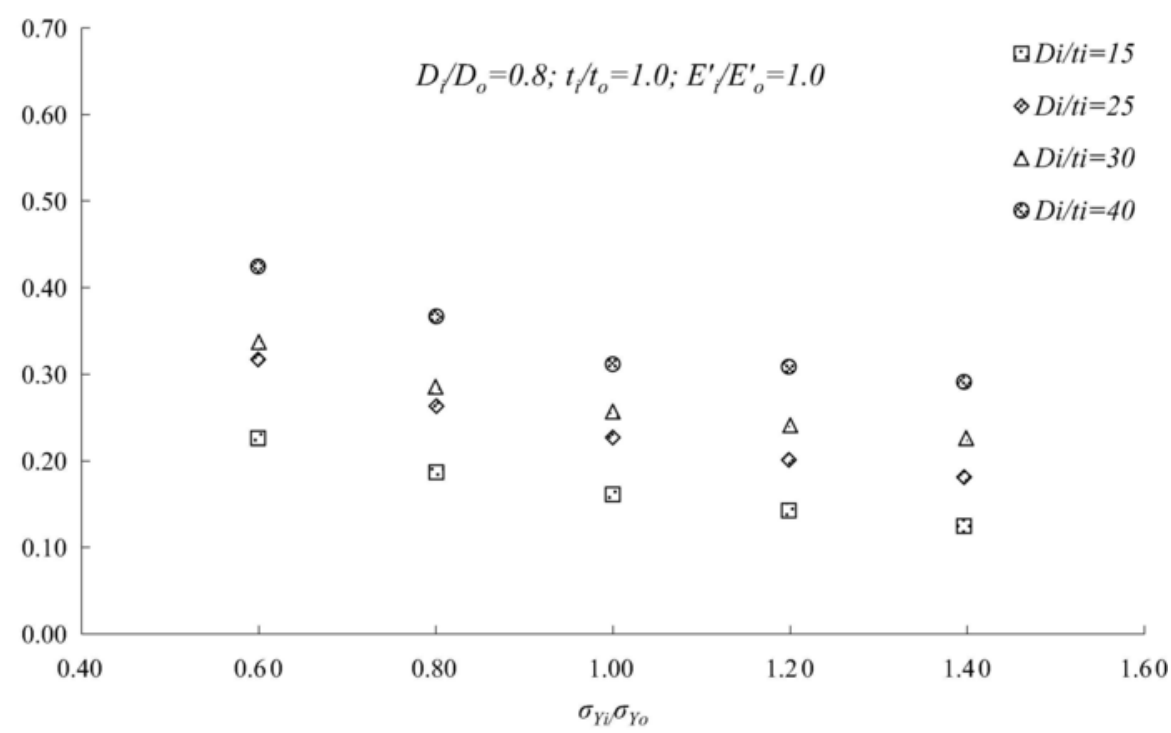

(b)

Fig. 10. Collapse pressure of the inner pipe as a function of $\sigma_{Y i} / \sigma_{Y O}$ with (a) $D_{i} / D_{o}=0.5$ and (b) $D_{i} / D_{o}=0.8$.

Also, a thorough examination of all buckle modes showed that, the distinction between failure modes $\mathrm{A}$ and $\mathrm{B}$ corresponds to $D_{o} / t_{o}=1.25$ $D_{i} / t_{i}$. This is confirmed through observation of failure mode B in hyperbaric chamber response of PIP-2 (Fig. 4), with $t_{i} / t_{o}=0.8, D_{o} / t_{o}=1.60$ $D_{i} / t_{i}$ and $\sigma_{Y i} / \sigma_{Y o}$ almost equal to one. An empirical expression for $P_{c i}$ was proposed and was shown to be in good agreement with hyperbaric chamber test results. Through combining all FE results, expressions for upper and lower bounds of the collapse pressure of the inner pipes were advised. 


$$
P_{c i} / P_{c r}
$$

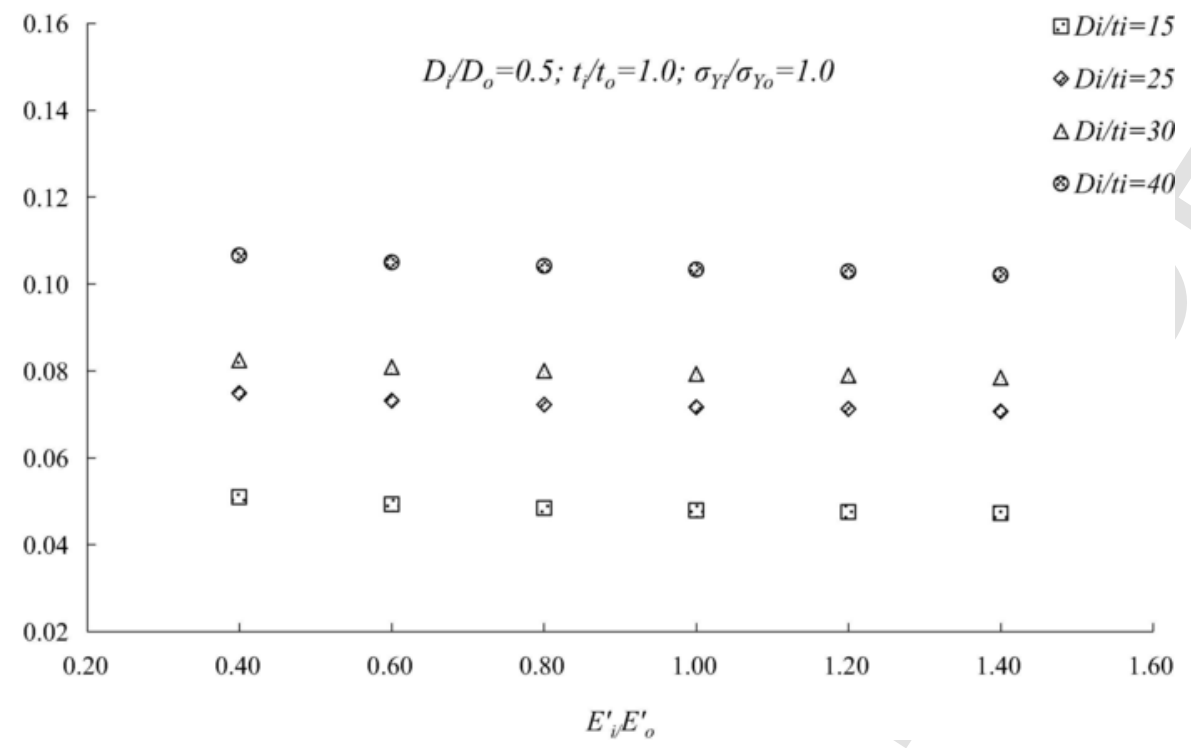

Fig. 11. Collapse pressure of the inner pipe as a function of $E_{i}^{\prime} / E_{o}^{\prime}$ with $D_{i} / D_{o}=0.5$.

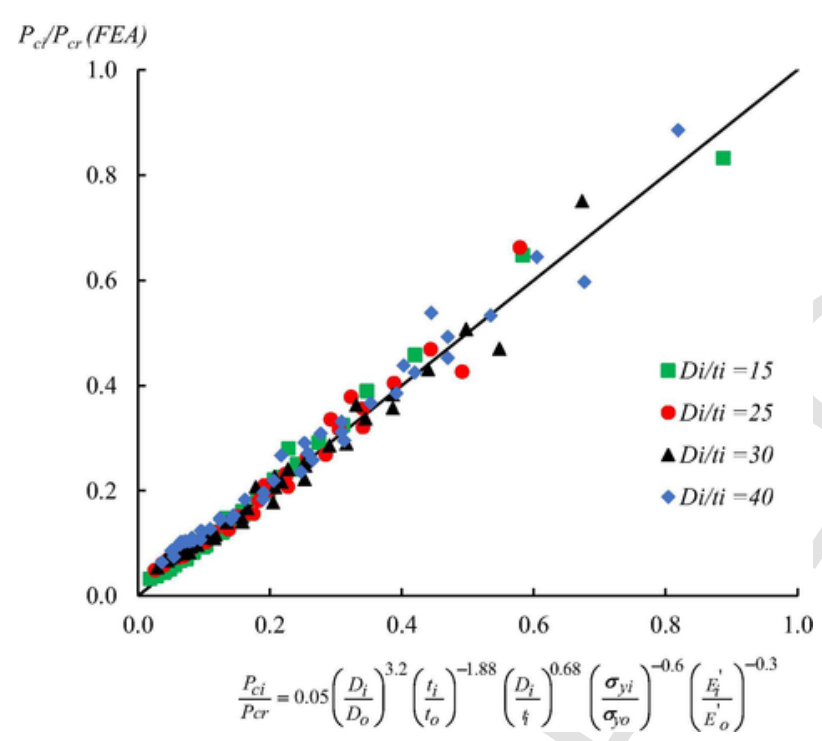

Fig. 12. Comparison between FE results and those predicted by Eq. (12).

Table 3

Comparison between empirical and experimental collapse pressures.

\begin{tabular}{llll}
\hline & $P_{c i} / P_{c r}($ Eq. (12)) & $P_{c i} / P_{c r}($ Exp.) & Difference (\%) \\
\hline PIP-1 & 0.173 & 0.166 & 4.05 \\
PIP-2 & 0.077 & 0.077 & 0.00 \\
PIP-3 & 0.188 & 0.184 & 2.13 \\
\hline
\end{tabular}




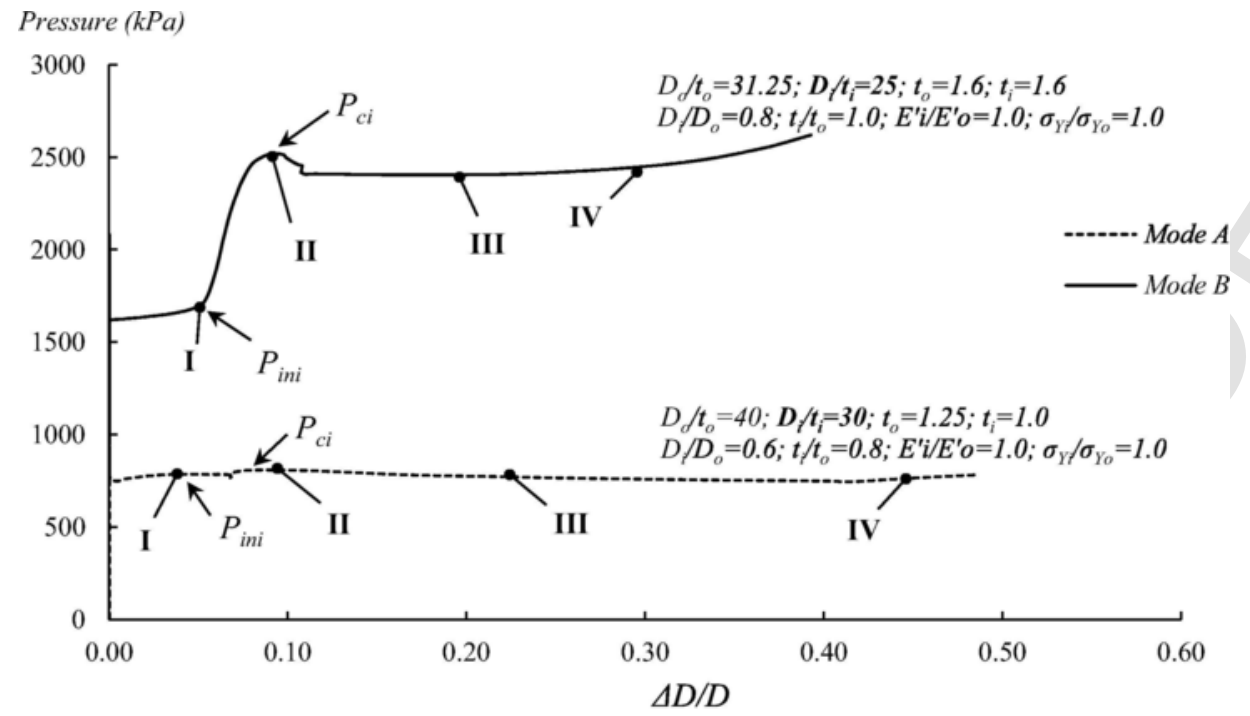

(a)

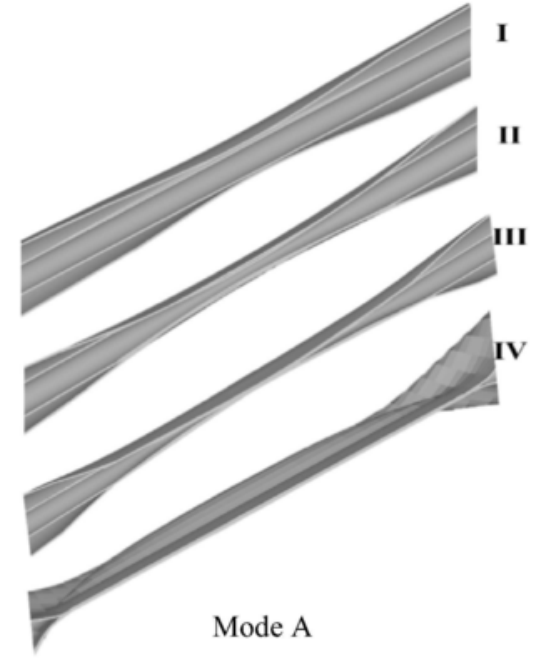

(b)

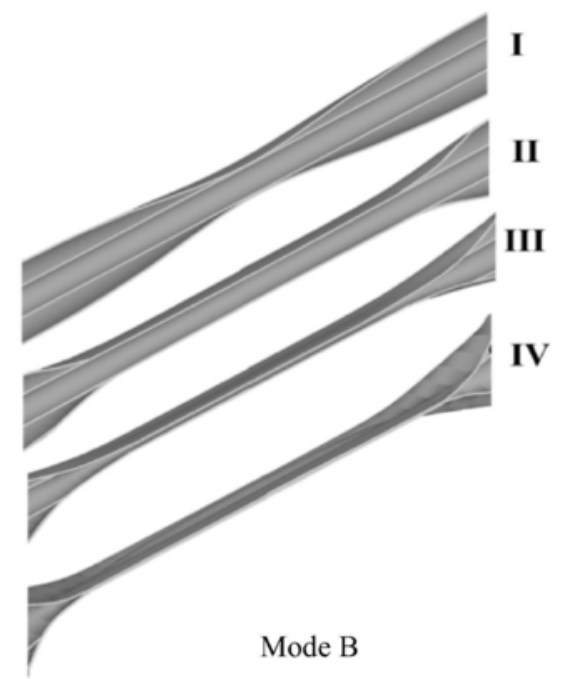

(c)

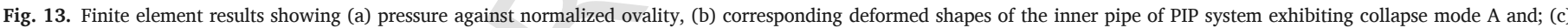
mode $\mathrm{B}$. 


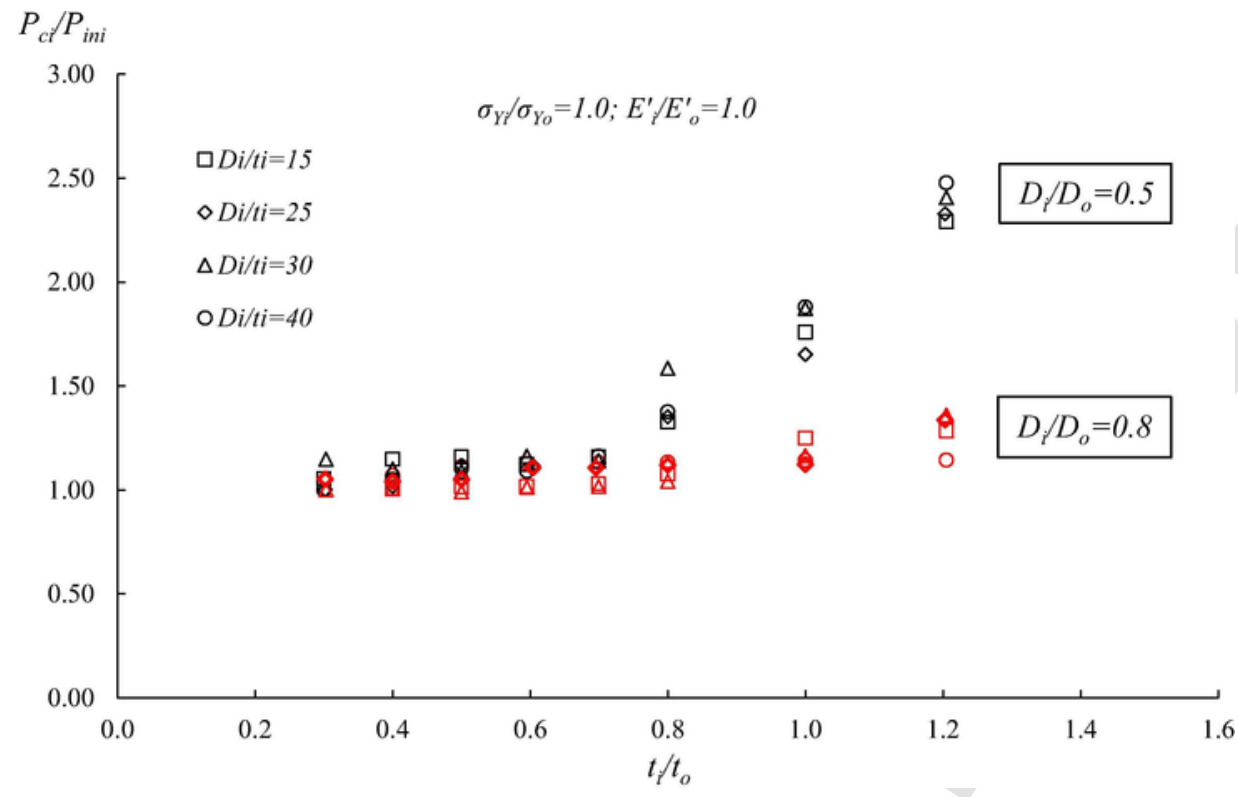

Fig. 14. Collapse pressures normalized by the initiation pressures of the inner pipe, showing effect of $t_{i} / t_{0}$.

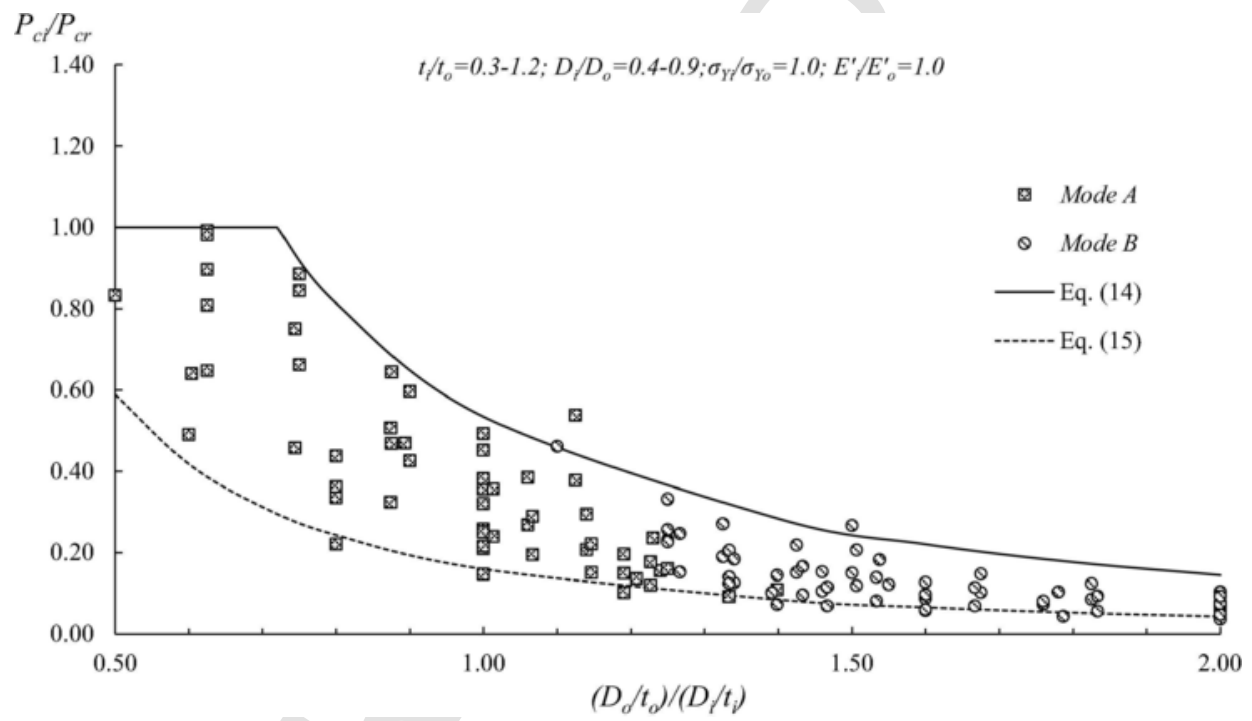

Fig. 15. Collapse pressures of the inner pipe against the normalized diameter-to-thickness ratios of outer and inner pipes of PIPs

\section{References}

[1] Y. Bai, Q. Bai (Eds.), Subsea pipelines and risers, Elsevier, 2005.

[2] A. Bokaian, Thermal expansion of pipe-in-pipe systems, Mar Struct 17 (6) (2004) 475-500.

[3] Jukes P, Eltaher A, Sun J, Harrison G. Extra high-pressure high-temperature (XHPHT) flowlines: design considerations and challenges. In: ASME 2009 28th International Conference on ocean, offshore and arctic engineering. ASME; 2009. p. 469-78.

[4] Z. Wang, Z. Chen, H. Liu, Numerical study on upheaval buckling of pipe-in-pipe systems with full contact imperfections, Eng Struct 99 (2015) 264-271.

[5] H. Karampour, F. Albermani, J. Gross, On lateral and upheaval buckling of subsea pipelines, Eng Struct 52 (2013) 317-330.

[6] M.A. Vaz, M.H. Patel, Lateral buckling of bundled pipe systems, Mar Struct 12 (1) (1999) 21-40.

[7] Z. Wang, Z. Chen, H. Liu, On lateral buckling of subsea pipe-in-pipe systems, Int J Steel Struct 15 (4) (2015) 881-892.

[8] H. Karampour, Effect of proximity of imperfections on buckle interaction in deep subsea pipelines, Mar Struct 59 (2018) 444-457.

[9] S.P. Timoshenko, J.M. Gere, Theory of elastic stability, McGrawHill-Kogakusha Ltd, Tokyo, 1961

[10] G.T. Ju, S. Kyriakides, Bifurcation buckling versus limit load instabilities of elastic-plastic tubes under bending and external pressure, J Offshore Mech Arct Eng 113 (1) (1991) 43-52.

[11] M. Fraldi, F. Guarracino, An improved formulation for the assessment of the capacity load of circular rings and cylindrical shells under external pressure. Part 1. Analytical derivation, Thin-Wall Struct 49 (9) (2011) 1054-1061.
[12] M. Fraldi, R. Freeman, S. Slater, A.C. Walker, F. Guarracino, An improved formulation for the assessment of the capacity load of circular rings and cylindrical shells under external pressure. Part 2. A comparative study with design codes prescriptions, experimental results and numerical simulations, Thin-Wall Struct 49 (9) (2011) 1062-1070.

[13] M.K. Yeh, S. Kyriakides, On the collapse of inelastic thick-walled tubes under external pressure, ASME J. Energy Resour. Technol 108 (1986) 35-47.

[14] R.E. Mesloh, J.E. Sorenson, T.J. Atterbury, Buckling and offshore pipelines, Gas 49 (1973) 7.

[15] A.C. Palmer, J.H. Martin, Buckle propagation in submarine pipelines, Nature 254 (5495) (1975) 46

[16] S. Kyriakides, C.D. Babcock, D. Elyada, Initiation of propagating buckles from local pipeline damages, J Energy Res Technol 106 (1) (1984) 79-87.

[17] F. Albermani, H. Khalilpasha, H. Karampour, Propagation buckling in deep sub-sea pipelines, Eng Struct 33 (2011) 2547-2553.

[18] P. Stephan, C. Love, F. Albermani, H. Karampour, Experimental study on confined buckle propagation, Adv. Steel Constr 12 (1) (2016) 44-54.

[19] H. Karampour, F. Albermani, M. Veidt, Buckle interaction in deep subsea pipelines, Thin-Wall Struct 72 (2013) 113-120.

[20] H. Karampour, F. Albermani, Buckle interaction in textured deep subsea pipelines, Ships Offshore Struct 11 (6) (2016) 625-635.

[21] H. Karampour, F. Albermani, Experimental and numerical investigations of buckle interaction in subsea pipelines, Eng Struct 66 (2014) 81-88.

[22] Karampour H, Albermani F, Major P. Interaction between lateral buckling and propagation buckling in textured deep subsea pipelines. In: ASME 2015 34th International conference on ocean, offshore and arctic engineering. ASME; 2015 
[23] S. Kyriakides, Buckle propagation in pipe-in-pipe systems: Part I. Experiments, Int J Solids Struct 39 (2) (2002) 351-366.

[24] S. Kyriakides, T.J. Vogler, Buckle propagation in pipe-in-pipe systems: Part II. Analysis, Int J Solids Struct 39 (2) (2002) 367-392.

[25] S. Gong, G. Li, Buckle propagation of pipe-in-pipe systems under external pressure, Eng Struct 84 (2015) 207-222.

[26] H. Karampour, M. Alrsai, F. Albermani, H. Guan, D.S. Jeng, Propagation buckling in subsea pipe-in-pipe systems, J Eng Mech 143 (9) (2017) 04017113.

[27] $\mathrm{T}$. Li, On the formulation of a finite element method for the general pipe-in-pipe structure system: Impact buckling analysis, Int J Mech Sci 135 (2018) 72-100.

[28] M. Alrsai, H. Karampour, F. Albermani, Numerical study and parametric analysis of the propagation buckling behaviour of subsea pipe-in-pipe systems, Thin-Wall Struct 125 (2018) 119-128.
[29] Australian Standard AS 1391-2007 (R2017) (Incorporating Amendment No. 1, 2017), Metallic materials - tensile testing at ambient temperature, Standards Australia, Sydney (NSW), 2007.

[30] S. Kamalarasa, C.R. Calladine, Buckle propagation in submarine pipelines, Int J Mech Sci 30 (1988) 217-228.

[31] DNV-OS-F101. Submarine pipeline systems; 2017.

[32] ANSYS 17.0 Release, Ansys Inc. 275 Technology Drive, Canonsburg, PA 15317.

[33] E. Riks, An incremental approach to the solution of snapping and buckling problems, Int J Solids Struct 15 (7) (1979) 529-551.

[34] S.F. Gong, X.Y. Ni, S. Bao, Y. Bai, Asymmetric collapse of offshore pipelines under external pressure, Ships Offshore Struct 8 (2) (2013) 176-188.

[35] T. He, M. Duan, C. An, Prediction of the collapse pressure for thick-walled pipes under external pressure, Appl Ocean Res 47 (2014) 199-203. 